\title{
Conhecimento, Verdade e Significado 1
}

\author{
Alexandre N. Machado \\ UFPR \\ alnor.machado@gmail.com
}

resumo 0 que se segue tem como objetivo expor um argumento de Wittgenstein contra uma versão do realismo filosófico, o realismo forte sobre a verdade. 0 argumento de Wittgenstein tem a forma geral de um modus tollens, cuja premissa condicional diz que 0 realismo forte sobre a verdade implica a hipótese do erro maciço. A negação do conseqüente está baseada na incompatibilidade entre a hipótese do erro maciço e a normatividade essencial da linguagem. Mas o argumento de Wittgenstein é compatível com uma versão fraca do realismo sobre a verdade. Na última secção eu examino o argumento de Stroud contra a tese suposta por Austin no seu argumento contra o ceticismo segundo a qual verdades sobre o modo de uso de "conhecimento" (e expressões correlatas) implicam verdades sobre o conhecimento. Procuro mostrar que o argumento de Stroud pressupõe a forma de realismo que alvo do argumento de Wittgenstein.

palavras-chave realismo; conhecimento; ceticismo; verdade; significado; Wittgenstein

\section{Introdução: Realismo}

Antes de mais nada, convém tentar deixar claro que tipo de realismo é o alvo do argumento crítico de Wittgenstein. Trata-se do realismo semântico. Mais precisamente, o realismo sobre a verdade. Não se trata, pois, nem do realismo metafísico, nem do realismo epistemológico.

O realismo metafísico é uma teoria sobre a natureza de um determinado tipo de entidades. Essa teoria tem duas teses principais, uma sobre a existência das entidades em questão e outra sobre a relação entre essa Recebido em 4 de março de 2009. Aceito em 15 de agosto de 2009. doispontos, Curitiba, São Carlos, vol. 6, n. 2, p.55-78, outubro, 2009 
existência e a nossa existência e/ou nosso conhecimento (ou nossas atitudes proposicionais, praticas lingüísticas, esquemas conceituais, etc.). $\mathrm{O}$ realismo sobre os universais, por exemplo, sustenta que os universais existem e sua existência é independente da nossa e do nosso conhecimento. O primeiro tipo de independência, a independência metafísica, implica o segundo tipo, a independência epistêmica, mas não vice-versa. Não há contradição em se dizer que um objeto é epistemicamente independente e metafisicamente dependente.

O realismo epistemológico é uma teoria sobre o conhecimento segundo a qual conhecemos entidades metafisicamente reais, isto é, entidades que existem e possuem independência metafísica e/ou epistêmica. Há quem chame de realismo filosófico a conjunção do realismo metafisico e do realismo epistemológico. ${ }^{2}$

O realismo semântico é uma teoria sobre a linguagem segundo a qual os valores semânticos, tais como o significado, a referência e os valores de verdade, são independentes de que os conheçamos. O externismo semântico (como o de Putnam ou de Burge, p.ex.) incorpora um realismo semântico, pois implica a possibilidade de que o usuário da linguagem não saiba, em parte, o que as suas expressões lingüísticas significam ou ao que elas se referem. (Algo análogo ocorre com o externismo sobre o conteúdo mental, uma teoria sobre mente, não sobre a linguagem.)

O realismo sobre a verdade (sobre os valores de verdade) é uma teoria segundo a qual os portadores de verdade (aquilo a que atribuímos verdade) têm os valores de verdade que têm independentemente de que saibamos quais são esses valores. Trata-se, pois, de uma tese sobre a relação entre a verdade (os valores de verdade) e o conhecimento. Essa independência da verdade em relação ao conhecimento pode ser concebida de maneira fraca ou forte. $\mathrm{Na}$ versão mais fraca, o realismo é simplesmente a recusa a reduzir a verdade, total ou parcialmente, à justificação. Qualquer negação de que a verdade possa ser extensional ou intensionalmente definida em termos da justificação seria uma versão fraca do realismo sobre a verdade. ${ }^{3} \mathrm{Na}$ versão mais forte, o realismo é a afirmação da possibilidade de haver verdade sem que haja qualquer conhecimento. A versão mais forte de realismo sobre a verdade, portanto, incorpora uma hipótese cética. Como veremos, a filosofia de Wittgenstein é uma maneira de se conciliar uma versão fraca do realismo com uma rejeição 
da sua versão forte. Segundo essa posição, não poderia haver verdade se não houvesse nenhum conhecimento, embora isso não seja porque a verdade é definida em termos da justificação. $\mathrm{O}$ realismo contra o qual se dirige o argumento de Wittgenstein, portanto, é o realismo forte sobre a verdade, na medida em que esse realismo incorpora uma hipótese cética.

\section{Realismo sobre a verdade}

A concepção realista da verdade, com já foi dito, seja sua versão forte, seja sua versão fraca, afirma que os portadores de verdade têm os valores de verdade que tem independentemente de que saibamos quais são esses valores.

\subsection{Portadores de verdade: proposições}

Há uma controvérsia sobre o que são os portadores de verdade, se frases, enunciados, asserções, proposições, crenças, pensamentos, juízos, etc. ${ }^{4}$ Dado que a argumentação que se segue não depende de se lidar com essa controvérsia, assumirei um critério minimalista para os portadores de verdade: eles são o que quer que seja expresso por frases que podem ser colocadas no lugar vazio do esquema

É verdade que

de tal forma que o resultado desse preenchimento seja uma frase com sentido (que expressa algo inteligível). Assim, "Chove", por exemplo, expressa algo verdadeiro ou falso porque "É verdade que chove" faz sentido. Mas "Que horas são?" e "Feche a porta" não expressam nada verdadeiro ou falso. ${ }^{5}$ Aquilo que frases desse tipo expressam é o que boas traduções dessas frases também expressam. ${ }^{6}$ Para efeitos de simplificação, vou chamar o que é expresso por frases que expressam algo verdadeiro ou falso de "proposição".

\subsection{Tese epistêmica}

Como vimos, há uma tese epistêmica na concepção realista da verdade que descreve a relação entre verdade e conhecimento. Ela afirma que as proposições possuem o valor de verdade que possuem, seja o verdadeiro seja o falso, de modo independente de que saibamos que valor de verdade 


\section{8}

é esse. As versões mais radicais do realismo sobre a verdade possuem um elemento modal na sua tese: as proposições possuem o valor de verdade que possuem de modo independente de que possamos saber que valor de verdade é esse. Algumas vezes o valor de verdade assim descrito é chamado de objetivo (dependente tão somente do objeto) e o conceito de verdade assim caracterizado é descrito como um conceito absolutamente não-epistêmico. A verdade assim concebida também é chamada de (possivelmente) transcendente, na medida em que (possivelmente) transcende nossa capacidade de conhecer a verdade.

\subsection{Tese metafisica}

Há uma tese metafisica contida na concepção realista da verdade. Ela afirma que uma proposição possui o valor de verdade que possui em virtude de uma realidade metafisicamente independente. É assim que, em uma passagem agora clássica, Dummett caracteriza o realismo sobre a verdade:

Realismo eu caracterizo como a crença que os enunciados da classe em disputa possuem um valor de verdade objetivo, independente dos nossos meios de conhecê-lo: eles são verdadeiros ou falsos em virtude de uma realidade existente independentemente de nós. $\mathrm{O}$ anti-realista opõe a isso a visão que os enunciados da classe em disputa devem ser entendidos apenas por referência à espécie de coisa que contamos como evidência para um enunciado dessa classe. [Dummett, 1963, 146]

A tese metafísica da concepção realista da verdade implica a teoria da verdade como correspondência, segundo a qual uma proposição é verdadeira porque corresponde a como a realidade é. Todavia, embora a concepção realista da verdade implique a teoria da verdade como correspondência, a teoria da verdade como correspondência não implica o realismo sobre a verdade, pois pode ser combinada com uma metafísica idealista. Um solipsista, por exemplo, pode sustentar que a verdade é correspondência com uma realidade dependente da sua mente. Dummett foi criticado por pensar que há uma equivalência entre a teoria da verdade como correspondência e a concepção realista da verdade. ${ }^{7}$

Embora incorpore um elemento metafísico, a concepção realista da verdade não implica o realismo metafisico. Um cético sobre a existência da verdade poderia sustentar uma concepção realista da verdade e uma 
metafísica idealista. Se essas duas teorias forem verdadeiras de modo geral, então a verdade será em geral impossível. ${ }^{8}$ Dummett também foi criticado por considerar o realismo sobre a verdade e o realismo metafisico como equivalentes. Todavia, embora prima facie haja um lugar para essa conjunção de teses no espaço das possibilidades lógicas, é difícil imaginar uma motivação para sustentá-las. Talvez isso explique ao menos parcialmente por que Dummett a tenha desconsiderado e tratado o realismo sobre a verdade e o realismo metafisico como equivalentes.

\subsection{Realismo filosófico e realismo do senso comum}

Agora devemos considerar uma ambigüidade geralmente não notada na formulação da tese epistêmica da concepção realista de verdade. A tese ambígua é:

(R) as proposições possuem o valor de verdade e que possuem, seja o verdadeiro seja o falso, independentemente de que saibamos que valor de verdade é esse

Uma das maneiras de se interpretar $\mathrm{R}$ é a seguinte:

(R1) Para toda proposição e todo sujeito cognoscente, é possível que essa proposição seja verdadeira e esse sujeito não saiba que ela é verdadeira.

Outra maneira de se interpretar $\mathrm{R}$ é a seguinte:

(R2) É possível que, para toda proposição e todo sujeito cognoscente, essa proposição seja verdadeira e esse sujeito não saiba que é verdadeira.

R1 pode ser parafraseada assim: qualquer proposição pode ser verdadeira sem que seja conhecida como verdadeira. Mas essa paráfrase não captura o conteúdo de R2, que pode ser parafraseada assim: é possível que todas as proposições sejam verdadeiras e ninguém saiba que são verdadeiras.

É claro que, para que R2 seja verdadeira, o domínio das proposições não deve conter uma proposição e sua negação, pois não é possível que todas as proposições de um domínio de proposições sejam verdadeiras se esse domínio contém uma proposição e sua negação, salvo se contradições podem ser verdadeiras. Com essa ressalva sobre o domínio do quantificador de R2 em mente, podemos ver que R1 não implica R2 embora R2 implique R1, ou seja, não são teses equivalentes. R1 
está dizendo algo de cada proposição, inclusive sua negação; está dizendo que cada uma pode ser verdadeira e não ser conhecida como verdadeira, não que, como diz R2, todas as proposições (de um certo domínio coerente) possam ser ao mesmo tempo verdadeiras e não serem conhecidas como verdadeiras.

Geralmente a concepção realista da verdade é formulada de maneira ambígua, sem deixar claro se a sua tese epistêmica deve ser entendida em termos de R1 ou de R2. Como já foi dito, a conjunção de R1 e a negação de R2 é consistente. Mas a negação de R2 implica alguma dependência da verdade em relação ao conhecimento. Se, por alguma razão, não pode ser o caso que todas as proposições de um domínio coerente qualquer de proposições sejam verdadeiras sem que se saiba que ao menos algumas delas são verdadeiras, então a verdade, de algum modo, depende do conhecimento. Podemos dizer que a tese R2 expressa uma independência absoluta da verdade em relação ao conhecimento, enquanto a tese R1 é compatível com uma dependência relativa, dado que é compatível com a negação de R2. A independência relativa seria aquela em que para que algumas proposições de um certo domínio sejam verdadeiras sem que sejam conhecidas como verdadeiras, outras proposições desse domínio devem ser conhecidas como verdadeiras.

Embora R1 seja uma tese realista fraca, ela ainda assim é forte o suficiente para ser contra-intuitiva. Não parece ser possível que uma pessoa não saiba, ao menos em alguns casos, se a frase "Sinto dor", por exemplo, dita por ela, seja verdadeira. O mesmo parece valer para "Se chove, então chove”. Mesmo Quine admitiu nos seus últimos escritos que há frases cujo significado é suficiente para que se saiba se são verdadeiras (embora essas frases não possam desempenhar o papel teórico que os defensores da analiticidade, tal como Carnap e Ayer, queriam que proposições analíticas desempenhassem e embora tais frases também estejam sujeitas, segundo Quine, à revisão). O realismo do senso comum, o realismo que contém as intuições contrárias a R1 recém mencionadas, é ainda mais fraco que R1.

Se R1 parece falsa, o que se dirá de R2? Para não parecer que se está argumentando contra um homem de palha, suponhamos que o domínio de proposições de R2 não apenas não contenha uma proposição e sua negação, mas tampouco contenha os aparentes contra-exemplos de R1. Um exemplo de tal domínio é a conjunção coerente das proposições 
sobre o mundo exterior e das proposições matemáticas, justamente os alvos da dúvida metódica cartesiana, tal como eu a entendo. ${ }^{9}$

\subsection{Realismo e erro maciço}

Mas dado que a concepção realista da verdade é, na verdade, uma concepção realista do valor de verdade, o que R2 diz sobre a verdade deve valer também para a falsidade. Portanto, a concepção realista da verdade implica R3:

(R3) É possível que, para toda proposição e todo sujeito cognoscente, essa proposição seja falsa e esse sujeito não saiba que é falsa.

Mas se toda proposição pode ser falsa e acreditamos que algumas delas são verdadeiras, então todas as nossas crenças podem ser falsas sem que saibamos que são falsas. Ou seja, a concepção realista da verdade conjuntamente com a tese que acreditamos que algumas proposições são verdadeiras implica a hipótese do erro maciço: ${ }^{10}$

(EM) É possível que, para toda proposição e todo sujeito cognoscente, esse sujeito acredite que proposição seja verdadeira e essa proposição seja falsa.

Se o domínio das proposições de EM for a conjunção coerente das proposições sobre o mundo exterior e das proposições matemáticas, então EM é a hipótese cética introduzida por Descartes, na primeira das suas Meditações, por meio do argumento do gênio maligno. ${ }^{11}$

\section{Erro maciço e normatividade}

Wittgenstein tem um argumento contra a hipótese do erro maciço e, por isso, contra o realismo semântico. A estratégia do argumento de Wittgenstein consiste em mostrar que essa hipótese é incompatível com a normatividade da linguagem. Mas, como já foi dito, a rejeição wittgensteiniana da concepção realista da verdade não está apoiada em uma redução (seja parcial, seja total) da verdade ao conhecimento. Wittgenstein não nega que, relativamente, a verdade seja independente do conhecimento. O que ele nega é que ela seja absolutamente independente 


\section{2}

do conhecimento, isto é, que haveria verdade mesmo que não houvesse nenhum conhecimento.

Se concebermos a asserção como um lance em um jogo de linguagem (como uma ação em uma prática lingüística), então o objetivo de Wittgenstein consiste em mostrar que não é possível que façamos apenas laces errados. Um modo paradoxal de se formular essa afirmação consiste em dizer: se todos os lances fossem errados, então nenhum seria errado. (Mas, como veremos, há um modo não paradoxal de formular essa afirmação.) Em uma passagem das Investigações Filosóficas, Wittgenstein expressa esse ponto da seguinte maneira:

'Se pode acontecer que alguém faça uma jogada errada em um jogo, poderia ocorrer que todas as pessoas em todos os jogos não fizessem nada mais do que lances errados.' Somos porém tentados aqui a entender mal a lógica da nossa expressão, a representar a aplicação de nossas palavras incorretamente.

Muitas vezes, ordens não são seguidas. O que ocorreria, todavia, se ordens nunca fossem seguidas? O conceito de "ordem" perderia sua finalidade. [Wittgenstein, 1958, \$345]

No último parágrafo, Wittgenstein fala de ordens. Ordens não são nem verdadeiras, nem falsas. Mas isso apenas mostra que o ponto sobre a normatividade para o qual estou chamando atenção ${ }^{12}$ é, segundo Wittgenstein, geral: usar a linguagem é realizar ações de acordo com regras. Uma dessas ações consiste em dizer coisas verdadeiras ou falsas; outra consiste em dar ordens.

Wittgenstein sustenta que inferir que o erro maciço é possível do fato que algumas vezes erramos é cometer um erro que é um caso especial do seguinte erro geral: concluir que algo pode ocorrer sempre do fato que ocorre algumas vezes.

Ele inicia a passagem citada acima dizendo justamente o seguinte:

"O que ocorre algumas vezes poderia ocorrer sempre." - Que espécie de proposição é essa? É como a seguinte: se ' $F(a)$ ' faz sentido, então ‘ $(x) \cdot F(x)$ ' faz sentido.

De acordo com Wittgenstein, há muitos contra-exemplos da tese que se " $F(a)$ " faz sentido, então “ $(x) \cdot F(x)$ " faz sentido. Não faz sentido pedir a 
alguém para escrever todos os números cardinais, embora faça sentido pedir que escreva algum número cardinal (cf. Wittgenstein (1974), p. 266). Outro exemplo é a suposição que o comportamento de alguém poderia ser sempre fingimento.

O primeiro passo para justificar a negação de (EM), é reconhecer alguns aspectos da relação entre a verdade e a prática de asserir.

\subsection{Verdade e asserção}

Podemos definir "asserção" de uma forma forte ou de uma forma fraca. A definição forte de asserção inclui a sinceridade: asserir é proferir uma frase do modo indicativo por meio da qual se expressa uma proposição que é tomada como verdadeira pelo proferidor. A definição fraca de asserção deixa lugar para asserções não sinceras: asserir é proferir uma frase do modo indicativo por meio da qual se expressa uma proposição. Quando mentimos ou somos irônicos, expressamos uma proposição por meio do proferimento de uma frase do modo indicativo, mas não tomamos a proposição expressa como verdadeira. De acordo com a definição forte de asserção, mentir ou ser irônico não envolve uma asserção, mas apenas o fingimento de uma asserção. De acordo com a definição fraca de asserção, mentir ou ser irônico envolve uma asserção não-sincera. Para o que pretendo discutir nesse ponto, não creio que faça diferença escolher entre uma das duas definições de "asserção". O ponto é: mentir e ser irônico são casos logicamente derivados em relação à sinceridade. Não é possível aprender a dizer mentiras ou a ironias antes de se aprender a dizer coisas com sinceridade. Não faz o menor sentido dizer que alguém sempre mentiu. ${ }^{13}$ Antes de aprender a mentir que $p$ (isto é, intencionalmente levar alguém a acreditar falsamente que se acredita que $p$ ) por meio do proferimento de da frase "p", deve-se aprender a dizer sinceramente que $p .{ }^{14}$ Uma maneira de se formular esse ponto é dizendo que a verdade é o objetivo da asserção, no sentido forte de "asserção". Outra maneira de se formular o mesmo ponto é dizendo que a verdade é o objetivo primitivo (embora não o único) da asserção, no sentido fraco de "asserção". Nesse sentido, não se pode ensinar alguém a asserir por meio de ironias ou mentiras. Uma criança não pode mentir que algo é branco, por exemplo, ou tampouco dizer com ironia que algo é branco, se não aprendeu a dizer sinceramente que algo é branco, ou 


\section{4}

seja, se não aprendeu a usar o predicado " $x$ é branco" tendo como objetivo de dizer a verdade.

Há outro caso em que usamos frases do modo indicativo e não temos o objetivo de dizer a verdade, a saber, como antecedentes e conseqüentes de condicionais. Mas podemos aprender a usar condicionais apenas depois de aprendermos a usar previamente suas frases componentes de forma sincera.

\subsection{Asserção e normatividade}

Dado que é o objetivo primitivo da asserção, a verdade determina o caráter normativo desse ato lingüístico. Mas o que significa dizer que uma atividade é normativa? Uma atividade é normativa, se se pode (faz sentido) avaliar uma ação como correta ou como incorreta em relação as regras constitutivas dessa atividade. Ou seja, uma atividade é normativa quando se segue regras ao realizá-la. ${ }^{15}$ Se A é uma atividade normativa, então faz sentido dizer que se faz A corretamente ou que se faz A incorretamente. Ela é realizada corretamente porque (embora não apenas porque) é realizada de acordo com a regra ou regras que são constitutivas de A. Ela é realizada incorretamente quando, ao tentar realizá-la, realizamos ações que não estão de acordo com as regras constitutivas de A. Mas fazer algo de acordo com essas regras não é suficiente para segui-las, pois esse acordo poderia ocorrer por acidente. ${ }^{16}$ Para segui-las deve-se tentar intencionalmente realizar as ações que estão de acordo com elas. Nesse sentido, uma máquina (um relógio, p.ex.) e objetos naturais não-intencionais (Terra, p.ex.) não podem seguir regras, embora possam comportar-se de acordo com elas, isto é, embora possam ter um comportamento regular (o relógio pode marcar a hora regularmente e a Terra pode girar em torno do Sol regularmente, p.ex.). Seguir uma regra não é o mesmo que seguila infalivelmente. Pode-se seguir uma regra cometendo-se alguns erros, como quando cometemos erros de aritmética. E não há razão para se pensar que deva haver uma fronteira precisa entre seguir uma regra cometendo-se erros e não segui-la.

Se concebemos a verdade como o objetivo primitivo de asserir, então assere-se corretamente se se diz a verdade, caso contrário assere-se incorretamente. Portanto, a regra primitiva que seguimos ao asserir é a seguinte:

(PR) Diga " $p$ " somente se $p$. 
Se alguém está tentando mentir, por exemplo, então não está tentando seguir PR. Mas a possibilidade de mentir é dependente da habilidade de seguir PR. É claro que, para seguir PR, uma pessoa deve acreditar que é o caso que $p$ (no caso de acreditar que deve dizer que $p$ ). Se ela acreditar que não é o caso que $p$, então ela não vai dizer " $p$ ", se está seguindo $\mathrm{PR}$. O mesmo vale para o caso de haver muitas dúvidas sobre se é o caso que $p \cdot{ }^{17}$

\subsection{Normatividade e significado}

Para Wittgenstein, o significado está essencialmente relacionado à normatividade. ${ }^{18}$ Esse ponto é normalmente expresso naquelas passagens nas quais ele diz que o significado de uma expressão é o seu uso. ${ }^{19}$ Muitas dessas passagens mostram que um aspecto central do que ele chama de "uso" é sua normatividade. ${ }^{20}$ Há uma passagem em que Wittgenstein o diz explicitamente: “Agir de acordo com a regra é FUNDAMENTAL para nosso jogo de linguagem. Isso caracteriza o que chamamos descrição" (Wittgenstein, 1996, 330).

Portanto, se o uso significativo de uma expressão é um uso normativo, no sentido recém explicado, então conhecer o significado de uma expressão envolve conhecer as regras que determinam o uso significativo dessa expressão. E conhecer as regras envolve aqui ser capaz de distinguir as ações que estão de acordo com as regras daquelas que não estão. Isso implica que se deve ser capaz de seguir essas regras, o que envolve ser capaz de realizar as ações que estão de acordo com a regra? Há casos em que se sabe quais ações estão de acordo com uma dada regra, embora não se seja capaz de segui-la, de realizar essas ações. Isso ocorre quando conhecemos a regra, digamos, "por descrição". ${ }^{21}$ Por exemplo: podemos saber se alguém tocou ou não a nota que, segundo uma certa partitura, ele deveria tocar sem saber tocar o instrumento que essa pessoa está tocando. Mas, de acordo com Wittgenstein, este é um outro exemplo do que poderia acontecer algumas vezes, mas não sempre. A capacidade de conhecer regras que não se é capaz de seguir pressupõe a habilidade de seguir regras. Para parafrasear Russell, para conhecer uma regra "por descrição", deve-se conhecer outras "por familiaridade", isto é, deve-se saber seguir efetivamente essas outras regras. Sendo assim, a posse de conhecimento semântico envolve a habilidade de seguir regras semânticas. ${ }^{22}$ 
Portanto, dado que, em casos primitivos, alguém usa um predicado corretamente se o usa para dizer a verdade, caso contrário o usa incorretamente, entender o significado de um predicado envolve, nesses casos, a habilidade de seguir as regras que determinam seu significado, isto é, envolve a habilidade de dizer a verdade usando o predicado. Se alguém é incapaz de dizer a verdade usando o predicado, então não compreende o predicado, a menos que seja um predicado cujo significado aprendeu-se "por descrição". Mas esse não é o caso de certos conceitos fundamentais tais como conceitos de cores e os números, por exemplo, ou como os próprios conceitos de verdade e conhecimento.

\subsection{Significado, falsidade óbvia e erro categorial}

Vamos olhar esse ponto mais de perto examinando alguns exemplos. Imagine que alguém diga "A neve é preta" enquanto olha para a neve. Talvez esteja sendo irônico ou esteja usando uma das palavras da frase, ou todas elas, em um sentido incomum. Mas suponha que perguntamos a essa pessoa sobre isso e ela diz que nada disso é o caso. Isso não mostraria que, afinal, a despeito das aparências, ela provavelmente não compreende alguma palavra da sua frase ou mesmo nenhuma delas? O ponto aqui é: não dizer a verdade em casos paradigmáticos da aplicação de um predicado é um critério para a falta de entendimento, a falta de sentido.

Em uma passagem de Zettel, que é paralela à passagem das Investigações citada acima, Wittgenstein nota que esse ponto pode ser expresso paradoxalmente:

Como pode ser que o sentido e a verdade (ou a verdade e o sentido) das proposições colapsem ao mesmo tempo? (Mantenham em pé ou derrubem um ao outro?).

E não é como se quiséssemos dizer: "Se isso e aquilo fosse o caso, então não faria sentido dizer que é o caso"?

Assim, p.ex.: "Se todos os lances fossem falsos, não faria nenhum sentido falar de um "movimentos falso". Mas esse é apenas um modo paradoxal de formular. O modo não paradoxal seria: "A descrição geral... não faz nenhum sentido”. [Wittgenstein, 1967, \$\$131-3]

O paradoxo de que fala Wittgenstein é o seguinte: como pode a frase “Todos os As são Bs" não fazer sentido no caso em que for verdadeira? 
Uma frase não deveria fazer sentido para que fosse verdadeira? Wittgenstein diz que a fim de expressar o ponto sem paradoxo, dever-se-ia dizer que a frase "Todos os As são Bs" não faz sentido e, portanto, não expressa nenhuma possibilidade.

Ele expressa esse ponto também de outro modo, através do conceito de erro: algumas vezes, quando não se diz a verdade por meio de uma frase, mesmo quando se almeja dizer a verdade, não é o caso que se esteja cometendo um erro; não porque haja algum espaço entre estar errado e estar correto, mas porque algumas vezes o fracasso na tentativa de se dizer a verdade é devido à falta (duradoura ou momentânea) de habilidade para seguir as regras relevantes. É verdade que, nesses casos, nós, que temos essa habilidade, podemos dizer que a frase em questão, "A neve é preta", por exemplo, é falsa ou que não é verdadeira. Mas isso não se deve ao fato de essa frase ser significativa na boca daquele que não sabe seguir as regras relevantes, mas porque nós sabemos como segui-las e, portanto, sabemos que dizer "A neve é preta" é fazer algo que não está de acordo com PR. O predicado "falsa" ou "não é verdadeira", nesse contexto, significa meramente que se está pronunciando uma frase que não está de acordo com as regras relevantes, o que não implica que a frase seja significativa na boca de quem a pronuncia.

Encontramos esse uso de "falso" também na avaliação de frases nas quais se comete o que se costuma chamar de "erro categorial". Por exemplo: poder-se-ia dizer que a frase "Meu pensamento tem um metro" é falsa. Mas ela não seria falsa porque meu pensamento tem outra extensão. Se alguém disser que meu pensamento tem um metro, não estará errado sobre a extensão do meu pensamento, mas simplesmente não saberá usar uma ou todas as palavras da frase "Seu pensamento tem um metro". Sendo assim, dizer que essa frase é falsa não é expressar a crença de que meu pensamento não tem um metro, como se ele pudesse ter alguma medida. O que a frase "Meu pensamento não tem um metro" poderia significar, exceto que não faz sentido dizer que meu pensamento tem um metro?23

Dizer que a neve é preta não é cometer um erro categorial. Não obstante, tal como erros categoriais, isso mostra que o falante não sabe como usar alguma palavra ou todas as palavras da frase. Mas se uma pessoa não sabe como usar uma palavra, então, a despeito das aparências 


\section{8}

em contrário, quando ela a usa, essa palavra não tem significado. Mas se ela não tem significado, então a frase em que a palavra é usada não tem sentido e, portanto, não é nem verdadeira nem falsa. Talvez haja uma diferença gradativa entre a habilidade máxima para usar uma palavra e a incapacidade total de usá-la corretamente. Mas não devemos perder o foco do que estamos examinando aqui: a possibilidade do erro maciço. Se o erro maciço fosse o caso no uso de um predicado, então não há dúvida que aquele que usa esse predicado é totalmente incapaz de usálo corretamente. Nesse caso, todas as frases nas quais ele usa esse predicado seriam desprovidas de sentido. Uma pessoa que não sabe seguir as regras do xadrez, não pode dar xeque-mate. Ela sequer pode iniciar uma partida de xadrez, mesmo que faça movimentos que estão de acordo com as regras do xadrez.

\subsection{Sumário do argumento}

Agora estamos em condição de sumariar o argumento de Wittgenstein contra a possibilidade do erro maciço e, por modus tollens, contra a concepção realista de verdade. Vimos que dizer a verdade é o objetivo primitivo da asserção e que o objetivo de se usar um predicado é asserir. Disso se segue que o objetivo primitivo de se usar um predicado é dizer a verdade, pois o objetivo primitivo de se usar um predicado é asserir. Vimos também que um predicado é usado corretamente quando é usado para dizer a verdade. Pode-se então concluir que se um predicado nunca é usado para dizer a verdade, então nunca é usado corretamente. Mas, se um predicado nunca é usado corretamente, então nunca é usado com sentido, pois o uso significativo de um predicado exige que se saiba seguir suas regras de uso e saber seguir suas regras de uso exige que se diga a verdade ao menos alguns casos paradigmáticos. Portanto, se um predicado nunca é usado para dizer a verdade, então nunca é usado com sentido. Ora, se, per impossibile, o erro maciço fosse o caso no uso de um predicado, então esse predicado nunca seria usado para dizer a verdade e, portanto, nunca seria usado com sentido. Mas se nunca fosse usado com sentido, as frases em que fosse usado não seriam nem verdadeiras nem falsas. Portanto, ou as frases que usamos para asserir têm sentido, mas nem todas (nem a maior parte) das nossas asserções são falsas, ou toda vez que usamos uma frase com o objetivo de asserir não dizemos algo verdadeiro, 
mas tampouco dizemos algo falso. Em qualquer dos dois casos, o erro maciço, a falsidade de todas as nossas asserções, está descartada. ${ }^{24}$

Se isso está correto e o realismo forte sobre a verdade implica EM, então o realismo forte sobre a verdade é falso. Mas isso significa que a verdade é de certa forma dependente do conhecimento, pois não haveria verdade se não houvesse nenhum conhecimento. Um corolário disso é que a hipótese cética motivada pelo argumento do gênio maligno apresentado na Primeira Meditação de Descartes não expressa uma possibilidade.

\section{Stroud e o ceticismo}

Barry Stroud, em seu livro clássico sobre o ceticismo filosófico (Stroud, 1984), não concorda com a última conclusão. No primeiro capítulo, ele apresenta o problema do ceticismo epistemológico sobre o mundo exterior a partir do argumento cartesiano do sonho. O problema é que, a partir de afirmações mais ou menos triviais, podemos inferir validamente que não podemos conhecer nada sobre o mundo exterior. Um suposto desse problema é que a hipótese cética é inteligível, expressa uma é possibilidade, ou, ao menos, assim parece ser. No segundo capítulo ("Philosophical Scepticism and Everyday Life"), ele procura responder ao argumento de Austin para mostrar que a hipótese cética não expressa uma possibilidade, na medida em que a crença que se trata de uma possibilidade baseia-se num mal-entendido sobre o conteúdo do conceito de conhecimento. ${ }^{25}$

A estratégia de Austin (1961) consiste em examinar o uso que fazemos da expressão "conhecimento" e expressões correlatas e mostrar que o argumento cético envolve uma violação das regras de uso dessa expressão. Isso mostraria que o cético, não estaria usando o mesmo conceito (não estaria usando a expressão "conhecimento" com o mesmo significado com) que nós usamos em contextos da vida cotidiana e contextos científicos. Mas se ele não está usando o mesmo conceito, então o que quer que sua conclusão diga, ela não diz nada sobre o que nos referidos contextos nós estamos chamando de conhecimento. Se ela diz que não é possível o conhecimento sobre o mundo exterior, então ela não diz que o que chamamos de conhecimento do mundo exterior 
nos referidos contextos não é possível. O cético estaria apresentando uma tese falsamente polêmica porque ele redefine um dos conceitos usados na sua formulação, como alguém que diz que não há médicos em Nova York e define "médico" como aquele que é capaz de curar qualquer doença. O que o cético faz, segundo Austin, é desconsiderar que, quando dizemos frases da forma "Sei que $p$ ", consideramos relevantes hipóteses incompatíveis com a verdade do que julgamos saber, para avaliar o uso dessas frases, apenas se essas hipóteses forem motivadas por razões especiais vinculadas ao contexto de proferimento dessas frases. A hipótese de que estamos dormindo, por exemplo, pode ser relevante quando dizemos que sabemos que alguém estava nos chamando porque estávamos meio dormindo no sofá e não temos certeza se ouvimos mesmo um chamado ou estávamos sonhando que ouvíamos um chamado. Se alguém nos perguntasse se sabemos que não estamos dormindo quando dizemos que sabemos que uma pessoa que acabou de nos telefonar vai vir à festa em que estamos, isso seria simplesmente ridículo. Também seria ridículo perguntar se sabemos que nosso amigo não será atingido por um meteorito no caminho para a festa (salvo se tiver havido chuvas de meteoritos recentemente). A pergunta sobre se sabemos que não estamos a dormir nos seria ininteligível nesse contexto (ou mesmo na maioria dos contextos científicos). Mas o argumento cético parece pressupor que deve ser sempre inteligível fazer uma tal pergunta sempre que alguém disser saber algo sobre o mundo exterior. Isso parece indicar que uma reflexão sobre o uso de frases da forma "Sei que $p$ " mostra que o conceito de conhecimento do cético é diferente do conceito ordinário e científico de conhecimento.

A estratégia da resposta de Stroud consiste em mostrar que a última conclusão é falsa. Para isso, ele se serve a da tradicional distinção cartesiana entre vida prática e busca pela verdade. Sua principal tese é que o fato de o uso de frases da forma "Sei que p" pressupor a ininteligibilidade de certas questões na avaliação do uso dessas frases não implica que essas questões não sejam relevantes para a avaliação da verdade ou falsidade dessas frases. Ou seja, Stroud supõe que os critérios para julgar a verdade ou falsidade dessas frases são independentes dos critérios de uso dessas frases, e vice-versa. Os critérios de uso dessas frases seriam por vezes constituídos por interesses não epistêmicos relacionados à vida prática. É por isso 
que perguntar se sei que não estou sonhando quando digo saber que meu amigo virá à festa é ridículo. É uma pergunta totalmente despropositada tendo-se em vista os interesses práticos do proferimento da frase "Sei que meu amigo virá à festa". De acordo com seus critérios de uso, seu proferimento pode estar plenamente justificado, mesmo que eu não saiba que ele não será atingido por um meteorito. Por isso, de acordo com esses mesmos critérios práticos, pode ser totalmente despropositado perguntar se eu sei que ele não será atingido por um meteorito no caminho para a festa, mesmo que a frase proferida seja de fato falsa, caso meu amigo seja atingido por um meteorito no caminho para a festa. Asserção justificada, portanto, não coincide necessariamente com conhecimento. As condições suficientes para a asserção justificada de "Sei que $p$ " podem estar satisfeitas sem que as condições para se saber que $p$ o estejam. O que o cético cartesiano está dizendo é que as condições do último tipo não podem ser satisfeitas, a despeito das condições do primeiro tipos freqüentemente estarem satisfeitas. Isso pressupõe que pode ser o caso que não sabemos nada sobre o mundo exterior, mesmo que a maior parte de nossas asserções sobre o mundo exterior sejam justificadas.

A razão alegada para que não saibamos nada sobre o mundo exterior é que uma condição necessária para esse conhecimento, saber que não estamos dormindo, aparentemente não pode ser satisfeita. Perguntar se essa condição está satisfeita em certos contextos em que se alega conhecimento pode ser pragmaticamente ininteligível, mas não é ininteligível, segundo o cético, se o que queremos é julgar se a alegação de conhecimento é verdadeira.

O exame desse debate entre Stroud e Austin é relevante aqui não apenas porque a tese cética que não sabemos nada sobre o mundo exterior implica a possibilidade do erro maciço no uso de qualquer predicado usado para descrever o mundo exterior, mas porque implica a efetividade do erro maciço no uso de frases da forma "S sabe que $p$ ", onde " $p$ " expressa uma proposição sobre o mundo exterior e $\mathrm{S}$ é um sujeito cognoscente qualquer (nós mesmos, por exemplo). Não se trata apenas de implicar que frases da forma "S sabe que $p$ " são falsas, mas de implicar que estamos sempre enganados ao dizer sinceramente que $\mathrm{S}$ sabe que $p$. Todas as nossas crenças da forma "S sabe que $p$ " seriam falsas, se a tese cética fosse verdadeira. Mas a pergunta que se impõe aqui é: como 
podemos saber o que é o conhecimento sobre o mundo exterior, se nos enganamos maciçamente toda vez que julgamos que alguém sabe que algo é o caso no mundo exterior? Como podemos saber o que é o conhecimento sobre o mundo exterior, se não conhecemos um caso sequer de conhecimento sobre o mundo exterior? Uma pessoa sabe o que é amarelo se julga sempre falsamente que algo é amarelo? Poder-seia dizer que essa última analogia é falsa porque não se trata de se julgar sempre falsamente que algo é a amarelo, mas apenas em um certo domínio. Estamos sempre enganados quando julgamos que algo é conhecimento do mundo exterior, não em todos os casos em que julgamos que algo é conhecimento. Sabemos o que é o conhecimento em geral a partir de casos de conhecimento de outro tipo. Mas qual tipo? Um candidato promissor aqui é o autoconhecimento, isto é, o conhecimento dos próprios estados mentais (o conhecimento lógico e matemático seriam outros candidatos). As proposições expressas pelas frases "Sei que sinto dor", "Sei que penso que $p$ ", "Sei que vejo vermelho", etc., quando pronunciadas com sinceridade, são sempre verdadeiras. Mas como podemos aprender que saber que uma proposição é verdadeira implica saber que todas as proposições incompatíveis com ela são falsas, dado que para aprender a usar as frases que expressam as chamadas proposições do autoconhecimento não aprendemos a nos certificar de que quaisquer proposições incompatíveis com elas são falsas? ${ }^{26}$ De onde vem a idéia que essa é uma condição necessária para o conhecimento?27

Além disso, essa exigência parece implicar um modelo circular de aprendizagem do conceito de conhecimento. Parece que para aprender o que é conhecimento, temos que aprender que ele envolve saber que as proposições incompatíveis com a proposição conhecida são falsas, ou seja, para aprender o que é conhecimento, devemos já estar de posse do conceito de conhecimento. Por outro lado, as condições para o conhecimento contidas nesse conceito de conhecimento parecem levar a um regresso ao infinito, pois se, para saber que $p$, temos que saber que todas as proposições incompatíveis com $p$, são falsas, então devemos saber que todas as proposições incompatíveis com todas as proposições incompatíveis com $p$ são falsas, e assim por diante, ad infinitum.

Sejam essas objeções decisivas ou não, o modo como Stroud analisa o conceito de conhecimento implica uma distinção entre significado e 
uso que está, no mínimo, comprometida com a possibilidade do erro maciço e, no máximo, com a efetividade desse tipo de erro em um caso fundamental: o uso de frases da forma "S sabe que $p$ ", onde " $p$ " é uma proposição sobre o mundo exterior. Isso significa que a análise de Stroud parece estar comprometida com a versão forte do realismo semântico, o alvo do argumento de Wittgenstein contra a possibilidade do erro maciço. E a análise de Stroud tem essas conseqüências porque está baseada numa distinção anti-wittgensteiniana entre significado e uso, o que é estranho vindo de um estudioso entusiasta da obra de Wittgenstein como é Stroud.

O diagnóstico wittgensteiniano das análises epistemológicas de Stroud tem semelhanças com um tipo de solução para o problema do ceticismo sobre o mundo exterior que ele denomina de argumento do caso paradigmático:

É desse modo, penso, que um filósofo cético responderia a qualquer argumento que parte da premissa que cada par de expressões $S$ e não-S é aplicada significativamente em diferentes ocasiões e chegam à conclusão que $S$ e não- $S$ devem ser aplicados verdadeiramente algumas vezes em tais ocasiões. Esse 'argumento do caso paradigmático' teve uma breve voga no auge da filosofia lingüística nos anos 1950. Parece haver um apelo a algo como ele na pergunta retórica de Austin "Como poderíamos usar e contrastar as palavras 'acordar' e 'sonhar' como o fazemos se não houvesse nenhum modo reconhecível de dizer em ocasiões particulares que não estamos dormindo?” Mas o argumento falha porque ele não dá conta de como e por que as expressões que usamos chegam a ser aplicados nos diferentes tipos de ocasiões em que as aplicamos. Pode haver diferenças facilmente discerníveis entre os dois tipos de ocasiões, e podemos aplicar uma expressão, ou sua negação, em uma ocasião com base apenas em tais aspectos discerníveis. Mas se certas suposições amplamente compartilhadas mas não examinadas são o que tornam possível ou desejável proceder desse modo, ou se certas restrições são atuantes [in force] que limitam nosso interesse a simplesmente traçar uma distinção particular entre dois tipos de ocasião, então embora estejamos determinando [making] uma diferença real entre a ocasião em que aplicamos $S$ e a ocasião em que aplicamos não-S, não se segue que a distinção que nós traçamos é de fato a 
distinção entre a aplicação verdadeira de $S$ em uma determinada ocasião e sua aplicação falsa. [Stroud, 1984, p. 74]

Se entendo bem essa passagem, Stroud está dizendo que os critérios para se distinguir entre quando é correto dizer que algo é $S$ e quando é correto dizer que algo não é $S$ não são os critérios para se dizer algo verdadeiro, na medida em o uso de tais critérios, por causa dos nossos interesses práticos, pode ser feito sob falsas suposições. Todavia, embora Stroud se preocupe com a pergunta sobre como e por que adotamos os critérios para se distinguir entre quando é correto dizer que algo é $S$ e quando é correto dizer que algo não é $S$, ele inexplicavelmente não parece preocupado com a pergunta sobre como adotamos os critérios para se distinguir entre dizer algo verdadeiro e dizer algo falso com frases da forma " $x$ é $S$ ". Como adquirimos o conceito de ser $S$ e, assim, pensar na possibilidade de que algo seja $S$ ou na possibilidade de que algo não seja $S$, se não temos nenhum exemplo de $S$ ? É claro que podemos aprender isso por meio de uma definição. Mas a questão importante é: por que adotamos uma definição em detrimento de outra? Como chegamos a saber que essa definição captura o conteúdo do conceito de ser $S$ ? Nesse caso, trata-se do conceito de ser conhecimento.

1 O presente artigo é uma versão expandida e revisada da secção 4 de Machado, 2007b. Gostaria de agradecer a Giovani Godoy Felice, Rogério Passos Severo, André Porto, Luiz Carlos Pereira, Roberto Horácio de Sa Pereira, Paulo Francisco Estrella Faria e Eros de Carvalho que, em momentos diferentes da realização dessa pesquisa, contribuíram com fecundos comentários e críticas.

${ }^{2}$ Ver Horwich, 1990, p. 55.

3 Uma definição intensional de "verdade" em termos de "justificação" seria uma definição de acordo com a qual "verdade" tem o mesmo significado ou conteúdo intensional e, portanto, a mesma extensão, que "justificação" ou que uma expressão complexa composta entre outras coisas pela expressão "justificação". Uma definição extensional de "verdade" em termos de "justificação" seria uma definição de acordo com a qual "verdade" tem a mesma extensão, mas não necessariamente a mesma intensão, que "justificação" ou que uma expressão complexa composta entre outras coisas pela expressão "justificação". Para uma explicação detalhada sobre esses dois tipos de definição, ver Kirkham, 1995, cap 1.

${ }^{4}$ Para uma apresentação crítica dessa controvérsia, ver Kirkham, 1992, cap. 2. 
5 Como bem notou Frege, perguntas que pedem um "sim" ou um "não" como resposta expressam uma proposição, embora elas não sejam asserções dessas proposições, mas um pedido para que outra pessoa assira essa proposição ou sua negação. Mas é por expressar uma proposição que faz sentido colocar "São 5 horas?”, por exemplo, no esquema acima: "É verdade que são 5 horas?”.

${ }^{6}$ E aqui também evito a discussão sobre se uma boa tradução é boa porque ela se expressa o mesmo que a expressão traduzida ou se ela expressa o mesmo que a expressão traduzida porque é uma boa tradução. Ou seja, evito aqui a discussão sobre se a identidade do conteúdo semântico é derivada da tradutibilidade (como pensa Quine) ou se a tradutibilidade é baseada na identidade do conteúdo semântico.

7 Cf. Devitt, 1991, 198 e Kirkham, 1995, 116.

8 Cf. Kirkham, 1995, 111.

${ }^{9}$ Para uma discussão sobre a natureza da dúvida metódica cartesiana, ver Machado, 2007d.

10 Em 2007 b procuro mostrar que o externismo de Putnam, exposto em 1975, incorpora uma forma de realismo filosófico que também implica a hipótese do erro maciço.

11 Poder-se-ia argumentar que Descartes não acreditava que fosse possível que a conjunção coerente das proposições sobre o mundo exterior e das proposições matemáticas fosse falsa, dadas as suas razões para excluir essa possibilidade apresentadas ao longo das cinco meditações restantes. Entretanto, os argumentos de Descartes não parecem mostrar que se trata de uma impossibilidade lógica ou conceitual, mas metafisica. Na Primeira Meditação Descartes parece justamente contar com o fato de se tratar de uma possibilidade lógica inteligível.

12 Uma explicação de "normatividade" e "normativo" encontra-se na secção 3.2.

13 E aqui temos outro contra-exemplo da tese que se " $F(a)$ " faz sentido, então " $(x) \cdot F(x)$ " faz sentido.

14 Em mais de uma ocasião Wittgenstein apela para reflexões sobre o que é possível na aquisição de certos conceitos a fim de exibir uma relação lógica entre eles. Ele afirma, por exemplo, que não se pode aprender a dizer "Isso parece $F$ " antes de aprender a dizer "Isso é F” (cf. Wittgenstein (1967), \$\$413-425). Por isso, não é possível que tudo seja, em última análise, aparência.

15 Ian Hanfling diz que "[u]ma ação, ou um modo de proceder, pode ser correto ou incorreto por uma variedade de razões, algumas envolvendo regras, outras não." (Hanfling, 1989, 148) Se o que ele quer dizer é que uma ação pode ser correta ou incorreta mesmo quando nada como o que Wittgenstein chamou de regra estrita está envolvido (cf. Wittgenstein, 1975b, p. 25), isto é, uma regra que determina condições necessárias e suficientes para o uso de uma expressão, então ele está correto. Mas não há nenhuma razão pela qual uma toda regra deveria ser uma regra estrita. Não há tampouco razão pela qual uma regra deveria poder ser formulada em uma frase. Pode-se explicar uma regra por meio de exemplos, por meio de uma série de aplicações da regra. Regras estritas são apenas um dos membros da família das regras.

16 Imagine um homem que não sabe o que é um semáforo e que, ao andar nas ruas, se distrai e para toda vez que o semáforo para pedestres mostra a luz vermelha acesa. Ele atravessa as 
ruas toda vez que o semáforo está mostrando a luz verde acesa. Esse homem age de acordo com as leis de trânsito, por puro acidente.

17 Agradeço ao Prof. Luiz Carlos Pereira por seus comentários sobre esse último ponto.

18 Saul Kripke enfatiza esse ponto no seu livro sobre Wittgenstein (cf. Kripke, 1982, e Boghossian, 1989).

19 Cf. Wittgenstein, 1996 , 257; 1974, 65; 1975b, 4; 1958, \$43. Algumas vezes se argumenta que em 1958, \43, Wittgenstein não está identificando significado e uso, pois ele diz "Para uma grande classe de casos, - embora não para todos - em que empregamos a palavra 'significado', ela pode ser definida assim: o significado de uma palavra é o seu uso na linguagem.” Mas creio que o que Wittgenstein está fazendo nessa passagem é apenas chamar a atenção para a ambigüidade da palavra "significado". Ela algumas vezes pode significar o mesmo que "importância”, como em "A palavra 'Deus' tem um grande significado para nossa cultura".

20 Cf. Wittgenstein, 1974, 53; 1975b, 11; 1958, \$\$207-208, 558.

21 Tomo emprestado aqui o par de expressões de Russell "por descrição" e "por familiaridade". Mas o faço aqui apenas para explicar o ponto em questão por meio de uma analogia. O que digo acima não me compromete com a epistemologia que Russell apresenta por meio desse par de expressões.

22 Horwich, 2002, argumenta que nem a verdade nem o significado são intrinsecamente normativos, embora tenham uma importância (import) normativa.É desejável acreditar no que é verdadeiro, mas não porque a verdade em si mesma seja normativa. Horwich formula a importância normativa da verdade e do significado por meios de duas teses: "(T) É desejável acreditar apenas no que é verdadeiro" e "(M) Se uma sentença significa que cães latem, é desejável aceitá-la apenas se cães latem; e se uma sentença signifca que matar é errado, devemos almejar aceitá-la apenas se matar é errado... e assim por diante”. (p.135) Se Wittgenstein está correto, então Horwich está errado, pois, como vimos, devemos almejar a verdade não porque elas seja útil, mas porque de outra forma seriamos incapazes de aprender a asserir.

23 Wittgenstein argumenta de forma análoga com relação à frase "Sei que tenho essa intenção": "E aqui 'sei' significa que a expressão de incerteza não tem sentido." (Wittgenstein, $1958, \$ 246)$

24 Em 2007a, procuro mostrar que o argumento de Burge para a tese que o aprendizado da linguagem requer atitudes proposicionais de re implica uma dependência da verdade em relação ao conhecimento análoga àquela que Wittgenstein julga existir. Para uma discussão mais detalhada dos argumentos apresentados aqui, cf. Machado, 2007c.

25 A idéia de confrontar os resultados anteriores com a crítica de Stroud a Austin foi uma sugestão do Prof. Eros de Carvalho. Agradeço a ele pelo que julgo ser uma excelente sugestão.

26 O caso é mais complicado no que se refere a proposições da forma "S sabe que pensa que $p$ ". Podemos descobrir por meio de sessões de psicanálise que pensamos que $p$. Mas, nesse caso, a proposição expressa por "S sabe que pensa que $p$ " está na mesma situação que qualquer proposição sobre o mundo exterior, pois está baseada em proposições sobre o mundo exterior: as proposições que descrevem o comportamento, verbal e não verbal, de S. Se esse for o caso, tais proposições não podem ser usadas pelo cético de Stroud como exemplos de conhecimento,

doispontos, Curitiba, São Carlos, vol. 6, n. 2, p.55-78, outubro, 2009 
dado que o cético de Stroud acredita que não há conhecimento sobre o mundo exterior.

27 Mutatis mutandis, essas perguntas podem ser feitas também no caso do conhecimento lógico e matemático.

\section{Referências bibliográficas}

AUSTIN, J.L. (1961) “Other Minds”, in:

Philosophical Papers. J.O.

Urmson \& G.J. Warnock (ed.) Oxford: Oxford University Press, cap. 4.

BOGHOSSIAN, P. (1989) “The Rule-Following Considerations”,

Mind, vol. 98, n. 392, pp. 507-549.

DEVITT, Michael. (1991) Realism and Truth. $2^{\mathrm{a}}$ ed. Princeton:

Princeton University Press.

DUMMETT, M. (1963) "Realism”, reimpresso em M. Dummett, (1978), Truth and Other Enigmas. London: Duckworth, pp. 145-165.

HANFLING, Oswald. (1989) Wittgenstein's Later Philosophy. London: MacMillan.

HORWICH, Paul. (2002) "Norms of Truth and Meaning", in:

SCHANTZ, Richard (org.). What is Truth? Berlin: Walter de Gruyter, pp. pp. 133-145.

. (1990) Truth. Oxford: Basil Blackwell.

KIRKHAM, Richard. (1995). Theories of Truth: A Critical Introduction. Cambridge: The MIT Press.

KRIPKE, Saul. (1982) Wittgenstein on Rules and Private Language. Oxford: Blackwell.

MACHADO, A.N. (2007a). "Sobre a Idéia Mesma de Pensamento De $R e$ : Reflexões a partir de Burge". Não publicado. Apresentado no III Colóquio Temático de Filosofia Analítica: Dinâmica Cognitiva e Pensamento De Re, UFRGS.

(2007b) "Wittgenstein e o Externalismo". in Plínio

J. Smith \& Waldomiro Silva Filho (org.). Ensaios sobre o Ceticismo. São Paulo: Alameda, pp. 194-226. 
. (2007c) Lógica e Forma de Vida:Wittgenstein e a Natureza da Necessidade Lógica e da Filosofia. São Leopoldo: Editora Unisinos. . (2007d) "Nota Sobre a Dúvida Cartesiana”. Dois

Pontos, vol. 4, n. 2, pp. 81-102.

PUTNAM, H. (1975) “The Meaning of 'Meaning”, in Philosophical Papers, vol. 2, Mind, Language, and Reality. Cambridge: Cambridge University Press, pp. 215-271.

STROUD, Barry. (1984) The Significance of Philosophical Scepticism. Oxford: Clarendon Press.

WITTGENSTEIN, Ludwig. (1958) Philosophical Investigations. G.E.M. Anscombe \& Rush Rhees (eds.), trad. G.E.M. Anscombe. Oxford: Blackwell.

(1967). Zettel. G.E.M. Anscombe \& G.H. von

Wright (eds.). Trad. G.E.M. Anscombe. Oxford: Basil Blackwell. . (1974). Philosophical Grammar. Rush Rhees (ed.).

Trad. A. Kenny. Berkeley \& Los Angeles: University of California Press. . (1975a). On Certainty. G.E.M. Anscombe \& G.H. Wright (eds.). Trad. Denis Paul \& G.E.M. Anscombe. Oxford: Blackwell. Blackwell. . (1975b). The Blue and Brown Books. Oxford: Basil . (1996). Remarks on the Foundations of Mathematics. Revised edition. G.H.Wright \& R. Rhees \& G.E.M. Anscombe (eds.). Trad. G.E.M. Anscombe. Cambridge, MA:The MIT Press. 